\title{
Coronary artery disease in patients dying from cardiogenic shock or congestive heart failure in the setting of acute myocardial infarction
}

Frans J. Wackers, K. I. Lie, Anton E. Becker, Dirk Durrer, and Hein J. J. Wellens

From the Departments of Cardiology and Pathology, University of Amsterdam, Wilhelmina Gasthuis, Amsterdam, The Netherlands

Pathological findings in the heart and particularly in the coronary arteries are reported from 70 patients dying from pump failure after acute myocardial infarction. Fifty of the patients had died in cardiogenic shock, the remainder from refractory congestive heart failure.

Three-vessel disease ( $\geqslant 75 \%$ occlusion) was present in 68 per cent of the group with cardiogenic shock but in only 35 per cent of those with fatal congestive heart failure $(P<0.02)$. In both groups there was an almost equal incidence ( $84 \%$ for cardiogenic shock and $80 \%$ for congestive heart failure) of severe disease ( $\geqslant 75 \%$ occlusion) over a long segment of the left anterior descending artery.

However, there were differences between the two groups regarding the involvement of the other coronary arteries. Whereas patients with cardiogenic shock generally showed severe disease over a long segment in all coronary arteries, in 60 per cent of those with congestive heart failure there was only local severe narrowing of the right coronary artery with little or no narrowing of the peripheral part. Similarly, 60 per cent of those with congestive heart failure had less than 75 per cent narrowing in the left circumflex artery. These anatomical findings may be of relevance with regard to desirability of acute coronary bypass surgery in patients with pump failure after acute myocardial infarction.

At present pump failure is the most important cause of hospital mortality in patients with acute myocardial infarction. Medical treatment of severe pump failure is often unsuccessful because of the presence of extensive myocardial damage (Harnarayan et al., 1970; Page et al., 1971; Alonso et al., 1973). Fatal pump failure after acute myocardial infarction occurs in two distinct clinical syndromes, namely cardiogenic shock and refractory congestive heart failure. Most patients die from cardiogenic shock, but some, without developing the clinical picture of cardiogenic shock, die from persistent refractory congestive heart failure. In order to treat these syndromes, several investigators have advocated use of circulatory assistance (such as intra-aortic balloon counterpulsation) followed by coronary bypass surgery (Dunkman et al., 1972; Scheidt et al., 1973; Miller et al., 1974; O'Rourke et al., 1975; Willerson et al., 1975). However, the efficacy of these procedures remains controversial (Cohen, 1974; Kuhn, 1974). It seemed to us that Received 28 January 1976. the success or failure of these measures could well relate to the underlying cardiac pathology. We have, therefore, studied the hearts of 70 patients who died either from cardiogenic shock or refractory congestive heart failure in the setting of acute myocardial infarction, paying particular attention to the state of the coronary arteries.

\section{Subjects and methods}

The material studied was derived from a group of 1050 patients consecutively admitted with acute myocardial infarction. Table 1 shows age, sex distribution, localization, and number of infarctions in patients who died from cardiogenic shock, congestive heart failure, necropsied and not necropsied, and other causes, and those who survived. Patients who died either from cardiogenic shock or other causes had a higher mean age $(P<0.05)$ than those who survived. Patients who died from cardiogenic shock and congestive heart failure had a higher incidence of both previous infarction $(P<0.01)$ and 
TABLE 1 Sex, age, number, and site of infarction in patients who died from cardiogenic shock, congestive heart failure, or other causes and in those who survived

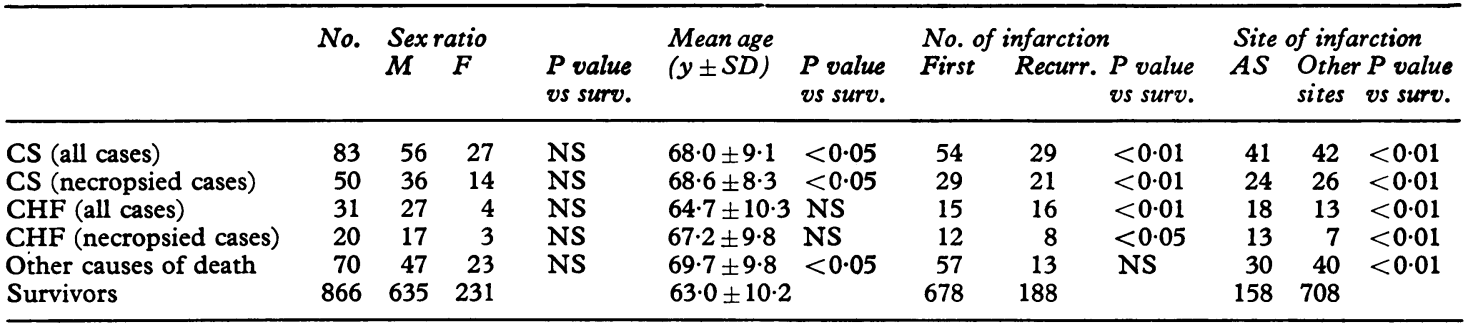

Abbreviations: $\mathrm{AS}=$ anteroseptal $\mathbf{C H F}=$ congestive heart failure $\mathrm{CS}=$ cardiogenic shock.

a higher incidence of anteroseptal infarction $(P<0.01)$ than those who survived.

One hundred and fourteen patients died from pump failure. Of these, 70 patients had necropsies and the hearts from these patients form the basis of this report. Fifty of these patients died of cardiogenic shock, while the 20 remaining patients died from refractory congestive failure.

Cardiogenic shock was defined according to Killip's (Wolk, Scheidt, and Killip, 1972) classification type IV: i.e. blood pressure under $90 \mathrm{mmHg}$ $(12.0 \mathrm{kPa})$, a decreased urine production of less than $20 \mathrm{ml}$ per hour, and signs of reduced peripheral circulation.

The group of patients with refractory congestive heart failure died in circumstances covered in Killip's classification by group II and III, i.e. persistent râles over both lung fields, with urine production maintained largely above $20 \mathrm{ml}$ per hour.

The diagnosis of acute myocardial infarction was based on a typical history of chest pain correlated with the appearance of diagnostic $Q$ waves and characteristic serial changes in serum enzymes.

Excluded from this study were all patients who died from pump failure secondary to ruptured papillary muscles or a ruptured ventricular septum, together with those with primary arrhythmias. In 52 of the 70 cases postmortem coronary angiograms were made. The right and left coronary arteries were selectively filled with a barium gelatin mixture at a pressure of approximately $40 \mathrm{mmHg}$ $(5.3 \mathrm{kPa})$. In addition, in each heart the coronary arteries were studied by serial sectioning at 3 to $5 \mathrm{~mm}$ intervals. Each section was inspected and the degree of luminal narrowing was determined, usually as a percentage of the external diameter. The observed pathology was reconstructed on drawings of the coronary arteries. Only obstructive lesions with more than a 75 per cent luminal narrowing were used for classification of coronary disease. A lesion was considered to be 'local' when only a single obstructive lesion was present, extending over a segment of $5 \mathrm{~mm}$ or less. Multiple obstructions or those extending over a segment longer than $5 \mathrm{~mm}$ were considered as 'diffuse' lesions. If possible (see under results) the size of the infarct was estimated grossly by inspection of the myocardium. When deemed necessary these findings were supplemented by microscopical studies. The significance of differences was analysed by use of the $\chi^{2}$ test. The significance of difference in mean values was tested by the Student's $t$ test.

\section{Results}

Age, sex, site, and number of infarcts for the 70 patients studied are shown in Table 1.

In terms of the onset of symptoms and moment of death, cardiogenic shock and refractory congestive heart failure constitute two clinically distinguishable groups (Fig. 1). Cardiogenic shock developed within 24 hours of onset of symptoms of acute myocardial infarction in 42 of 50 patients $(84 \%)$. In contrast, fatal congestive heart failure developed over a 3-week period after onset of acute myocardial infarction $(P<0.01)$. Eighty-six per cent of patients with fatal cardiogenic shock died within 24 hours of its onset and 98 per cent died within 3 days. In contrast, only 20 per cent of patients with fatal congestive heart failure died within 24 hours $(P<0.01)$, 25 per cent $(P<0.01)$ dying within 3 days of the onset of symptoms (Fig. 2).

\section{Size of infarction}

Determination of the size of the myocardial infarct was hampered in those patients dying within 24 hours of onset of infarction since the extent of the infarct could not be determined with certainty. For this reason, in only 28 cases (11 patients with cardiogenic shock and 17 patients with congestive 
Onset after A.M.I.

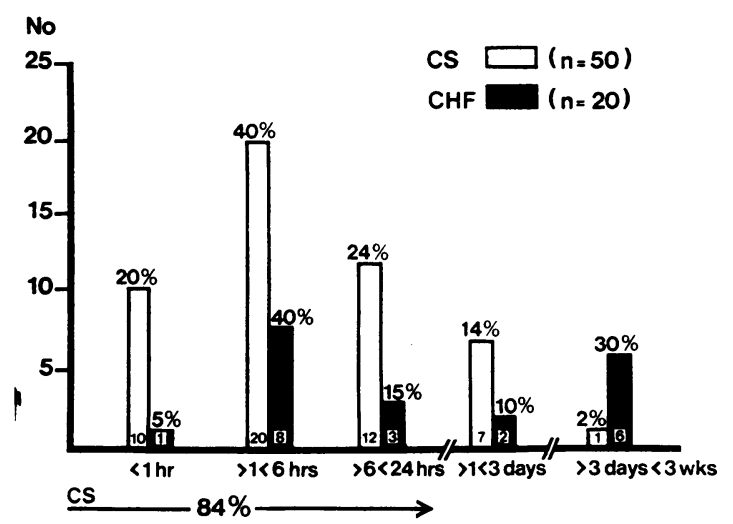

FIG. 1 Time of onset of cardiogenic shock (CS) after first symptoms of acute myocardial infarction ( $A M I)$ as compared with the time of onset of lethal congestive heart failure (CHF).

heart failure) was it possible to analyse infarct size. No major difference in size of infarcted myocardium was found between the group with cardiogenic shock and that with congestive heart failure. In both groups a 40 to 50 per cent involvement of left ventricular myocardium was present. The papillary muscles were involved in the infarction in 5 hearts from patients dying with congestive heart failure.

\section{Coronary artery pathology}

Severe atherosclerotic involvement of the coronary arteries was present in hearts obtained both from patients with cardiogenic shock and from those

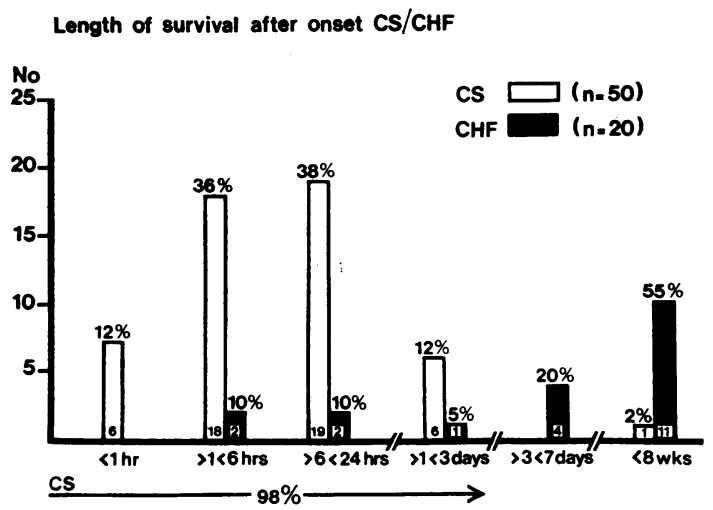

FIG. 2 Length of survival after onset of cardiogenic shock (CS) and lethal congestive heart failure (CHF).
TABLE 2 One, two, or three-vessel coronary artery disease ${ }^{\star}$ in patients dying from cardiogenic shock $(N=50)$ and in those dying from congestive heart failure $(N=20)$

\begin{tabular}{|c|c|c|c|c|c|c|}
\hline$C A D$ & $\begin{array}{l}\text { One } \\
\text { No. }\end{array}$ & $\%$ & $\begin{array}{l}\text { Two } \\
\text { No. }\end{array}$ & $\%$ & $\begin{array}{l}\text { Threc } \\
\text { No. }\end{array}$ & e \\
\hline $\begin{array}{l}\text { CS } \\
\text { CHF }\end{array}$ & $\begin{array}{l}0 \\
4\end{array}$ & 20 & $\begin{array}{r}16 \\
9\end{array}$ & $\begin{array}{l}32 \\
45\end{array}$ & $\begin{array}{r}34 \\
7\end{array}$ & $\begin{array}{l}68 \\
35\end{array}$ \\
\hline
\end{tabular}

Abbreviations: $\mathrm{CAD}=$ coronary artery disease; $\mathrm{CHF}=$ congestive heart failure; $\mathrm{CS}=$ cardiogenic shock.

$\star$ Luminal narrowing of $\geqslant 75$ per cent.

dying with refractory congestive heart failure (Table 2).

The left anterior descending coronary artery was always diseased. Usually, this artery was heavily calcified and exhibited severe stenosis of a diffuse type, often complicated by total occlusion. The two clinical groups showed no differences regarding the degree and extent of involvement of the anterior descending artery. However, striking differences between the two clinical groups were noted with regard to the severity and extent of sclerotic disease in the other arteries. In patients with congestive heart failure the left circumflex artery and the right coronary artery were less involved than in patients with cardiogenic shock (Table 3).

Obstructive lesions in the right coronary artery and the left main stem in patients with congestive heart failure were mostly of a localized type $(<5 \mathrm{~mm})$ and were confined to the proximal parts of the arteries. Patients with cardiogenic shock, in

TABLE 3 Severity of luminal narrowing of coronary arteries in patients dying from cardiogenic shock $(N=50)$ and congestive heart failure $(N=20)$

\begin{tabular}{|c|c|c|c|c|c|c|}
\hline & & $\begin{array}{l}\text { Lur } \\
<7 \\
\text { No. }\end{array}$ & $\begin{array}{l}\text { inal } \\
\% \\
\%\end{array}$ & $\begin{array}{l}\text { owin } \\
\geqslant 7 \\
\text { No. }\end{array}$ & & $\begin{array}{l}P \text { value } \\
C S \text { vs } C H F\end{array}$ \\
\hline \multirow{2}{*}{ RCA } & CS & 4 & 8 & 46 & 92 & \multirow{2}{*}{$<0.01$} \\
\hline & CHF & 6 & 30 & 14 & 70 & \\
\hline \multirow{2}{*}{ LMS } & CS & 31 & 62 & 19 & 38 & \multirow{2}{*}{ NS } \\
\hline & CHF & 16 & 80 & 4 & 20 & \\
\hline \multirow{2}{*}{ LAD } & & 0 & & 50 & 100 & \multirow{2}{*}{ NS } \\
\hline & CHF & 0 & & 20 & 100 & \\
\hline \multirow{2}{*}{ LCA } & $\mathrm{CS}$ & 13 & 26 & 37 & 74 & \multirow{2}{*}{$<0.01$} \\
\hline & CHF & 12 & 60 & 8 & 40 & \\
\hline
\end{tabular}

Abbreviations: $\mathrm{CHF}=$ congestive heart failure; $\mathrm{CS}=$ cardiogenic shock; $L A D=$ left anterior descending artery; $L C A=$ left circumflex artery; $\mathrm{LMS}=$ left main stem; $\mathrm{RCA}=$ right coronary artery. 
TABLE 4 Length of segment involved in coronary artery disease ${ }^{\star}$ in patients dying from cardiogenic shock $(N=50)$ and in those dying from congestive heart failure $(N=20)$

\begin{tabular}{|c|c|c|c|c|c|c|}
\hline & & $\begin{array}{l}<5 \\
\text { No. }\end{array}$ & & $\begin{array}{l}\geqslant 5 \\
\text { No. }\end{array}$ & $\begin{array}{l}n m \\
\%\end{array}$ & $\begin{array}{l}P \text { value } \\
C S \text { vs } C H F\end{array}$ \\
\hline \multirow{2}{*}{ RCA } & & 11 & 22 & 35 & 70 & \multirow{2}{*}{$<0.01$} \\
\hline & CHF & 12 & 60 & 2 & 10 & \\
\hline \multirow{2}{*}{ LMS } & $\mathrm{CS}$ & 3 & 6 & 16 & 32 & \multirow{2}{*}{$<0.01$} \\
\hline & $\mathrm{CHF}$ & 4 & 20 & 0 & & \\
\hline \multirow{2}{*}{ LAD } & $\mathrm{CS}$ & 8 & 16 & 42 & 84 & \multirow{2}{*}{ NS } \\
\hline & CHF & 4 & 20 & 16 & 80 & \\
\hline \multirow{2}{*}{ LCA } & $\mathrm{CS}$ & 16 & 32 & 21 & 42 & \multirow{2}{*}{ NS } \\
\hline & CHF & 5 & 25 & 3 & 15 & \\
\hline
\end{tabular}

Abbreviations: $\mathrm{CHF}=$ congestive heart failure; $\mathrm{CS}=$ cardiogenic shock; $\mathrm{LAD}=$ left anterior descending artery; $\mathrm{LCA}=$ left circumflex artery; $L M S=$ left main stem; $R C A=$ right coronary artery.

$\star$ Luminal narrowing of $\geqslant 75$ per cent.

contrast, had atherosclerotic changes of diffuse type in both these arteries (Table 4). Three-vessel disease was present in 68 per cent of the patients dying from cardiogenic shock, but in only 35 per cent of the patients dying from congestive heart failure $(P<0.02)$. One-vessel disease was present in 20 per cent of patients with congestive heart failure, but did not occur at all in patients with cardiogenic shock (Table 2).

It was not possible to identify differences in either severity or extent of coronary artery pathology between patients with 'early' cardiogenic shock (i.e. onset within 24 hours of acute myocardial infarction) and those dying from 'late' cardiogenic shock (i.e. onset of shock later than 24 hours of acute myocardial infarction).

\section{Discussion}

For the most part, our data endorse the well-known fact that patients who die from pump failure in the setting of acute myocardial infarction have extensive loss of myocardium and severe coronary artery disease (Bolooki et al., 1971; Alonso et al., 1973; Scheidt et al., 1973; Buja and Roberts, 1974; Willerson et al., 1975). However, our study additionally shows that important differences exist with regard to localization and extent of coronary artery disease between patients dying in cardiogenic shock and those dying in congestive heart failure. To the best of our knowledge, this finding has not been stressed previously. Both groups of patients had similar severe involvement of the left anterior descending coronary artery. In the majority of patients who died of refractory congestive heart failure $(60 \%)$, there was minor involvement of the right coronary artery, representing only a localized narrowing with little or no distal involvement. In patients who died from cardiogenic shock there was severe diffuse involvement of this artery. These differences in extent of coronary artery disease were also noted between the two groups with regard to the left circumflex artery.

It is possible that these anatomical findings may have therapeutic implications. In recent years more aggesssive approaches have been advocated in the treatment of the patient with severe pump failure complicating acute myocardial infarction (Dunkman et al., 1972; Scheidt et al., 1973; Miller et al., 1974; O'Rourke et al., 1975). It has been suggested that circulatory assist should be initiated followed by acute bypass surgery. Differences in reported results undoubtedly relate primarily to the extent of the myocardial damage. Our findings are in accordance with those described by Harnarayan et al. (1970), in that the extent of the infarction is similar in both patients dying from congestive heart failure and from cardiogenic shock. An explanation for the differences in clinical course, in the setting of a similar infarct size, could be that in these patients with congestive heart failure after their primary myocardial infarct, a gradual extension of the infarcted area leads to fatal congestive heart failure.

Our findings suggest that, because of the differences in coronary artery involvement, early coronary bypass surgery is far more likely to be of benefit in patients with refractory congestive heart failure than in patients with cardiogenic shock. The early recognition of the group of patients with pump failure presenting as refractory congestive failure therefore becomes of crucial importance. The problem remains as to how these patients are to be detected in the immediate postinfarction period. Our study revealed that patients who developed congestive heart failure did so over a long period of time, with no initial clinical signs which might have indicated the fatal outcome. They differed completely from patients with cardiogenic shock who for the most part developed their complication within 24 hours of the acute infarction. They also generally died within a few days. In an attempt to determine the profile of those patients with congestive heart failure who are at high risk, we noted that 77 per cent of patients dying from failure had either an anteroseptal infarction or a recurrent infarction. The prognostic significance of these factors has been reported previously (Lie et al., 1974, 1975). In addition, the outcome for 
these patients is largely determined by whether or not they respond to medical treatment. If they do not respond, refractory congestive heart failure in the setting of an acute myocardial infarct is a bad prognostic sign. Our findings, therefore, stress the necessity for careful study of the group of patients who develop refractory congestive heart failure after acute infarction in order to identify that subgroup of patients in which the outcome will be fatal.

\section{References}

Alonso, D. R., Scheidt, S., Post, M., and Killip, T. (1973). Pathophysiology of cardiogenic shock. Quantification of myocardial necrosis, clinical, pathologic and electrocardiographic correlations. Circulation, 48, 588.

Bolooki, H., Lemberg, L., Ghahramani, A., Economides, C., Caldwell, T., and Jude, J. R. (1971). Clinical, surgical and pathologic correlation in patients with acute myocardial infarction and pump failure. Circulation, 44, 1034.

Buja, L. M., and Roberts, W. C. (1974). The coronary arteries and myocardium in acute myocardial infarction and shock. In Shock in Myocardial Infarction, pp. 1-22. Ed by R. M. Gunnar, H. S. Loeb, and S. H. Rahimtoola. Grune and Stratton, New York.

Cohen, L. S. (1974). Current status of circulatory assist devices. American fournal of Cardiology, 33, 316.

Dunkman, W. B., Leinbach, R. C., Buckley, M. J., Mundth, E. D., Kantrowitz, A. R., Austen, W. G., and Sanders, C. A. (1972). Clinical and hemodynamic results of intraaortic balloon pumping and surgery for cardiogenic shock. Circulation, 46, 465.

Harnarayan, C., Bennett, M. A., Pentecost, B. L., and Brewer, D. B. (1970). Quantitative study of infarcted myocardium in cardiogenic shock. British Heart fournal, 32, 728.

Kuhn, L. A. (1974). 'Salvage' with assisted circulation in acute myocardial infarction and shock. American fournal of Cardiology, 34, 873.
Lie, K. I., Tans, A. C., Louridtz, W. J., Durrer, D., and Wellens, H. J. J. (1975). Immediate prognosis in recurrent myocardial infarction. Lancet, 1, 647.

Lie, K. I., Wellens, H. J. J., Schuilenburg, R. M., Becker, A. E., and Durrer, D. (1974). Factors influencing prognosis of bundle branch block complicating acute anteroseptal infarction. Circulation, 50, 935.

Miller, M. G., Weintraub, R. M., Hedley-Whyte, J., Restall, D. S., and Alexander, M. (1974). Surgery for cardiogenic shock. Lancet, 2, 1342.

O'Rourke, M. F., Chang, V. P., Windsor, H. M., Shanaham, M. X., Hickie, J. B., Morgan, J. J., Gunning, J. F., Seldon, A. W., Hall, G. V., Michell, G., Goldfarb, D., and Harrison, D. G. (1975). Acute severe cardiac failure complicating myocardial infarction. Experience with 100 patients referred for consideration of mechanical left ventricular assistance. British Heart fournal, 37, 169.

Page, D. L., Caulfield, J. B., Kastor, J. A., DeSanctis, R. W., and Sanders, C. A. (1971). Myocardial changes associated with cardiogenic shock. New England fournal of Medicine, 285, 133.

Scheidt, S., Wilner, G., Mueller, H., Summers, D., Lesch, M., Wolff, G., Krakauer, J., Rubenfire, M., Fleming, P., Noon, G., Oldham, N., Killip, T., and Kantrowitz, A. (1973). Intra-aortic balloon counterpulsation in cardiogenic shock: report of a co-operative clinical trial. New Ergland fournal of Medicine, 288, 979.

Willerson, J. T., Curry, G. C., Watson, J. T., Leshin, S. J., Ecker, R. R., Mullins, C. B., Platt, M. R., and Sugg, W. L. (1975). Intraaortic balloon counterpulsation in patients in cardiogenic shock, medically refractory left ventricular failure and/or recurrent ventricular tachycardia. American fournal of Medicine, 58, 183.

Wolk, M. J., Scheidt, S., and Killip, T. (1972). Heart failure complicating acute myocardial infarction. Circulation, 45, 1125.

Requests for reprints to Dr. Frans J. Wackers, Department of Cardiology, University of Amsterdam, Wilhelmina Gasthuis, Amsterdam, The Netherlands. 